\title{
Raz on rights: human rights, fundamental rights and balancing
}

Article

Accepted Version

Zanghellini, A. (2017) Raz on rights: human rights, fundamental rights and balancing. Ratio Juris, 30 (1). pp. 2540. ISSN 1467-9337 doi: https://doi.org/10.1111/raju.12156 Available at https://centaur.reading.ac.uk/45898/

It is advisable to refer to the publisher's version if you intend to cite from the work. See Guidance on citing.

To link to this article DOI: http://dx.doi.org/10.1111/raju.12156

Publisher: Wiley

All outputs in CentAUR are protected by Intellectual Property Rights law, including copyright law. Copyright and IPR is retained by the creators or other copyright holders. Terms and conditions for use of this material are defined in the End User Agreement.

\section{www.reading.ac.uk/centaur}

\section{CentAUR}

Central Archive at the University of Reading

Reading's research outputs online 


\title{
Raz on Rights: Human Rights,
}

\section{Fundamental Rights and Balancing}

ALEARDO ZANGHELLINI*

\begin{abstract}
After clarifying the outlines of Raz's interest theory of rights and its relationship to aspects of the principles theory of rights, I consider how his recent observations on human rights fit (or fail to fit) into the interest theory. I then address two questions. First, I elaborate on Raz's definition of morally fundamental rights, arguing that he is right in claiming that there are no such rights. I then show that the interest theory accommodates the notion that rights may take qualitative precedence over conflicting considerations - a question that has become increasingly relevant in light of recent writing on rights.
\end{abstract}

\section{Introduction}

This article has the twofold aim of showing that the explanatory power of Raz's interest theory of rights (ITR) is undiminished, but that some aspects of the theory call for clarification and elaboration. I begin by sketching the outlines of the theory and show how it relates to and illuminates some aspects of the principles theory of constitutional rights. Although the ITR applies to all rights, debates about rights tend to foreground our important rights. Since it is often assumed that these largely coincide with those listed in human rights documents, I will review some of the points Raz makes on human rights. I will show that Raz's aims and methodology in developing a theory of human rights practice diverge from those that informed his formulation of the ITR. I shall then discuss those rights that have a

\footnotetext{
* Professor of Law and Social Theory, University of Reading. Many thanks to Denise Meyerson for her comments on an early draft, to Stuart Lakin for our discussions on balancing and to the anonymous referees for their helpful feedback.
} 


\section{RAZ ON RIGHTS}

stronger claim to being considered our most important rights: morally fundamental rights. Raz's definition of morally fundamental rights as self-grounding rights is conceptually unexceptionable. However, I will try to substantiate Raz's recent claim that there are probably no such rights. I will then turn to work that emphasises "qualitative" rather than "quantitative" methods of resolving conflicts involving rights. I will argue that Raz's ITR accommodates, both logically and terminologically, the idea that sometimes rights take qualitative precedence over conflicting considerations.

\section{The ITR and the principles theory}

Raz's ITR is offered as a philosophical definition of rights, or an analysis of the concept of right as used in "legal, political, and moral writing and discourse" (Raz 1986, 165). It aims to apply to all rights - whether important or not, and whether moral or legal (Raz 1984).

According to Raz, individual interests are ground for rights and rights are grounds for duties, duties being peremptory reasons for action. A right exists only if an interest of the right-holder - ie, an aspect of her well-being - is of sufficient importance to hold others to be under a duty (Raz 1984a, 195-6). Thus, although rights are not the only grounds of duties, to each right corresponds at least one duty. Frequently, however, to a right correspond several duties and the duties are lesser than the duty to secure the object of the right (Raz 1984a, 199). For example, my right to be a parent may ground a duty in third parties not to stop me from reproducing, but it does not require that I be secured a child.

In order for an individual interest to successfully ground a right the reasons for action prompted by the importance of that interest must not be nullified by counter-considerations. Raz puts it in terms of a judgement about the importance of that individual interest relative to the importance of any relevant counter-consideration: 


\section{RAZ ON RIGHTS}

Where the conflicting considerations outweigh the interest of the would-be right-holder ... then there is no right. Where the conflicting considerations override those on which the right is based on some but not all occasions, the general core right exists but the conflicting considerations may show that some of its possible derivations do not. (Raz 1984a, 211)

This passage also points to an important element in the structure of rights - the fact that one can think of individual interests as grounding core rights from which further, more specific rights can be derived (Raz 1984a, 197-9). Although Raz does not spell this out, derivative rights can be stated at different levels of specificity. Thus, the core right to be a parent grounds a more specific right to apply for adoption. This right - call it an "intermediate right" - may in turn ground a right to have policies which unjustifiably prevent certain classes of people from applying for adoption changed.

One question is to what extent the distinction between core rights and derivative rights maps onto the differentiation between prima facie and definitive rights developed by Alexy (2002), whose principles theory of constitutional rights has become increasingly influential. For Alexy (2002) rights can take either the form of principles (60), that is "norms which require that something be realised to the greatest extent possible, given the legal and factual possibilities" (47) or rules, that is "decisions about what is to happen within the realm of the legally and factually possible" (57). Generally (but not invariably) rights as declared in constitutions take the form of principles. Principles can and do conflict; and they are general, in the sense that "they have not been related to the possibilities of the factual and normative world" (Alexy 2002, 60). As such, for adjudicators a principle is only a reason for declaring a prima facie right in the person who invokes it. Conflicts between principles and the concrete prima facie "ought" statements that they justify (including prima facie rights) ${ }^{1}$ are definitively

\footnotetext{
${ }^{1}$ Not all prima facie "ought" statements justified by principles are reducible to individual rights.
} 


\section{RAZ ON RIGHTS}

resolved only in light of the circumstances of the concrete case, by deciding which principle carries the day in that set of circumstances (Alexy 2002, 54). This decision, establishing a "preference relationship" between competing principles, takes the form of a rule; if the principle preferred articulates a right (rather than some other kind of value), then the rule enables the transition from the would-be right-holder having a prima facie right to her having a definitive right. In these cases the rule establishing the preference relation definitively provides (at least if the rule admits of no exceptions) that a certain right holds (or that a certain act is a violation of that right) when certain circumstances obtain - circumstances under which those of the case in which the rule is announced can be subsumed (Alexy 2002, 50-60). Assuming this rule enjoys "correct constitutional justification", then it is a constitutional rights norm no less than one directly established in the constitution: it is a “derived constitutional rights norm" (Alexy 2002, 56).

Despite appearances, there is no correspondence between core rights and prima facie rights, or between derivative and definitive rights. Prima facie rights are no less derivative than definitive rights: both are concrete ought statements to the effect that a derivative right either may be (in the case of prima facie rights) or is (in the case of definitive rights) derived from (ie justified by) the right articulated as a principle in the relevant constitutional provision. Indeed, from the perspective of the ITR, a prima facie right is, strictly speaking, not a right, its ability to ground duties being purely hypothetical and unable to be confirmed until a definitive right is established. As to the right articulated as a principle in the relevant constitutional provision, and from which prima facie and definitive rights are derived, it may be a core right, but it could also be, to use the terminology I employed above, an intermediate right: it depends on the level of generality at which the constitutional principle is stated. Thus in terms of the ITR, one could say that constitutional and human rights adjudication tends to 


\section{RAZ ON RIGHTS}

involve assessments about the existence of specific derivative righs from core or intermediate rights in light of relevant counter-considerations.

The distinction between prima-facie and definitive rights has recently been used to argue that decision-making bodies should be very liberal in recognising as prima-facie entitlements the constitutional or human rights claimed by those who allege a violation of such rights - without prejudice to the question of whether or not a corresponding definitive right is eventually found (Kum 2006, 12; Möller 2012, 3). Möller $(2012,24)$ argues that this ensures that "all autonomy interests survive the prima facie stage in order to assess the adequacy of their protection at the justification stage". This move has been criticised on the grounds that it requires the courts to legislate, as it were, on everything (Tsakyras 2013) and that rights "should be understood in such a way as to be in harmony with the moral universe that gives them sense" (Webber 2013, 19). The ITR vindicates this critique. First, rights are grounded in interests, understood as aspects of people's well-being; secondly, interests do not ground rights unless they are of sufficient importance to override counter-considerations and ground duties. It may be argued that the latter point only becomes relevant at the point of establishing whether a definitive right exists; but the former applies even at the prima facie stage. This circumstance shows the vacuity of the claim that "it is coherent to accept" a prima facie right to murder (Möller 2012, 24). As I argued above, the ITR entails that prima facie rights are not technically rights; but it also suggests that a right to murder is not even a prima facie right and twice removed from being an actual right.

The ITR also throws light on other aspects of the principles school of thought. Consider the idea that within each constitutional rights "something like a "center of resistance' exists which ... [protects] minimum core contents of rights", so that "[v]ery serious interferences can hardly ever be justified by raising the weight of the justifying reasons" (Klatt and Meister 2012a, 68). Thus stated the point has a touch of the esoteric about 


\section{RAZ ON RIGHTS}

it; and no less than the "law of diminishing marginal utility" and the "Nash Social Choice Function" have been rallied up in its support (Klatt and Meister 2012a, 68). But the point is logically entailed by the ITR. Unless a right can ground at least one duty, it is no right. Thus, entrenching a right in a constitution commits a legal system to at least minimal duties of nonviolation of the right. Taking the view that the right grounds a modicum of peremptory reasons not to violate it - those most intimately connected to the value of the interest grounding the right - is a sine qua non for it to continue to exist as a constitutional right at all.

In addition to arguing that interest ground rights, rights ground duties and core rights ground derivative rights, the ITR makes two further important points. First, rights are dynamic: they generate duties whose content may vary depending on circumstances (Raz 1984a, 199-200). In the constitutional context, this idea accounts for Alexy's $(2002,54)$ point that preference relations between principles are established in light of the concrete circumstances of the case. We have seen that when a constitutional rights dispute arises, the decision-maker needs to establish a preference relation between competing principles, so as to decide which of the prima facie concrete ought statements justified by the competing principles should prevail. Since the dispute involves rights, at least one of those statements will be a prima facie right; and since rights are grounds for duties, the decision-maker will effectively be deciding whether a specific duty of non-violation or promotion of the right holds. Because the duties that rights ground vary depending on context, this explains why preference relations generally need, as Alexy $(2002,54)$ argues, to be established in light of the concrete circumstances of the case. But the dynamism of duties goes beyond illuminating the point of the context-dependency of preference relations; by drawing attention to diachronic change rather than simply synchronic variability of circumstances, it also accounts for evolutionary interpretation in constitutional adjudication. 


\section{RAZ ON RIGHTS}

Secondly, although it is a distinctive feature of rights that they are grounded in some interest of the right-holder's, sometimes that interest is considered sufficiently important to ground a right because of its instrumental, rather than intrinsic, value (Raz 1984a 206-7). This requires some elaboration. Since individual interests are aspects of people's well-being, and people's well-being is of intrinsic and ultimate value (Raz 1984a, 205-6), the importance of an individual interest grounding a right will always, it seems, be partly a function of the interest's intrinsic value. But the interest may be of value also because pursuing it will or may bring about beneficial consequences, either to the right-holder or others. In these cases we would say that the interest also has instrumental value, and this instrumental value may play a role in determining the overall importance of the interest. Thus, to continue with my example, the interest in a life with children, which grounds the right to be a parent, is intrinsically valuable (a life with children is an intrinsically valuable form of life), but it is also instrumentally valuable to the right-holder (eg, one's children may provide financial support in one's old age). Pursuing an individual interest may also result in benefiting people other than the interest-holder. The right to adopt is a good illustration, for adoptable children benefit from the fact that their prospective parents have a right to adopt. But rights can be instrumentally valuable to society at large too, particularly by creating the conditions for the flourishing of collective goods (Raz 1984a, 206-7). For Raz, often the reason why we assign individual interests the importance necessary to successfully ground rights is that we believe that protecting these interests is beneficial to others in just this way.

Raz (1984a, 208) maintains that rights provide us with a shared moral vocabulary even if we may not agree on the interests grounding the rights or the detailed content of the duties grounded by them. If so, rights have an important integrative function- a point missed by the critique of rights stemming from the traditions of communitarianism and critical theory. 


\section{RAZ ON RIGHTS}

\section{Human rights and the ITR}

When talking about rights we often have in mind what we consider our morally "important" rights - the kind protected in human rights documents. Raz, however, draws important distinctions between the concept of morally fundamental rights and the practice of human rights. Raz's remarks on morally fundamental rights, offered as part of his analysis of the concept of right as used in moral, legal and political writing, amount to a philosophical definition. But Raz (2007; 2010; 2013) - whose views on human rights have proved controversial (Schaber 2011; Liao and Etinson 2012; Tasioulas 2013; Waldron 2013) - does not treat human rights in the same way. In this section I draw less attention to the content of his substantive arguments on human rights than to the goal and methodological approach orienting them. I do so to show the severability of his reflections on human rights from the ITR.

Raz $(2007,19)$ maintains that elucidating the meaning of the "concept of a human right" fails to "illuminate significant ethical or political issues." He means that philosophical theories of human rights do not (analytically, as opposed to rhetorically) do any ethical or political work: without them, we can come to the same (or sounder) ethical or political conclusions. Rather than elucidating the philosophical concept of human rights, Raz's theorising about such rights takes the cue from the practice of human rights - he observes it in order to be able to assess it. ${ }^{2}$

Raz takes issue with the "traditional" approach to human rights theorising. This approach tries to make sense of the proposition that human rights are those universal rights that we have merely by virtue of our humanity ( $\operatorname{Raz} 2010,37$ ), generally identifying these rights in light of a certain conception of personhood. But the approach fails to establish that

\footnotetext{
${ }^{2}$ Without saying so, $\operatorname{Raz}(1986,2567-62)$ also applied this methodology when discussing constitutional rights.
} 


\section{RAZ ON RIGHTS}

many of the rights it considers human rights are universal and derived from personhood, or that we hold them by virtue of being human ( $\operatorname{Raz} 2007,4-8,40)$.

If the task of a theory of human rights is to enable us to evaluate the practice of human rights, traditional theories also fail because they are disconnected from the practice. Critically assessing the practice of human rights requires that we look at "the essential features" that the "practice attributes to the rights it acknowledges to be human rights" (Raz 2007, 8), as the features of a practice may "affect the considerations by which it should be judged" (Raz 2013, 7). Hence the starting point for a theory of (the practice of) human rights must be the practice itself, not a certain understanding of human nature or personhood.

Raz $(2007,9)$ identifies as the "dominant trend" in human rights practice the fact that these rights are treated as "a defeasibly sufficient ground for taking action against violators in the international arena." Thus, human rights are that subset of rights whose violation a state cannot - as a matter of sound morality - justifiably treat as merely an internal matter by invoking sovereignty; and human rights practice can be assessed on the basis of whether or not it justifiably treats the violation of certain rights as "sovereignty-limiting measures" (Raz $2007,10)$. The fact that sound morality is the ultimate arbiter shows that there is no question here of inferring an 'ought' from an 'is' in the sense that would be fatal to Raz's account of human rights. Raz's approach uses an empirical fact (that human rights practice treats these rights as justifying sovereignty-liming measures) in order to decide what human rights practice is about and to explicate what it means for it to do well. The practice does well when it correctly treats, morally speaking, certain rights as justifying sovereignty-limiting measures. Assessing if the practice measures up to this standard no doubt requires us to take into account both normative considerations and empirical facts; but when the standards to

critically assess the practice are operationalised, there is no derivation of normative 


\section{RAZ ON RIGHTS}

consequences ('this right should be treated as a human right') from the empirical fact that a particular right is treated as "human" by the practice.

Whether or not the violation of certain rights justifies sovereignty-limiting measures depends not only on whether a state, by violating the right, has overstepped its authority, but also on the "the contingencies of the current system of international relations" (Raz 2007, 19). Therefore, Raz $(2007,19)$ provocatively concludes, human rights "lack a foundation in not being grounded in a fundamental moral concern." This remark should not be taken literally. All rights, according to the ITR, are grounded in aspects of people's well being; since human well-being is, according to humanistic moralities, of ultimate value, all rights are grounded in (aspects of) the most fundamental moral concern. What Raz means, I think, is that being grounded in a fundamental moral concern is not the watershed between human rights and other rights; it is the fact that human rights justify interference with state sovereignty that sets them apart from other rights. But what morally justifies such interference is largely a function of changeable features of international politics.

\section{Morally fundamental rights}

Although human rights, thus identified, must be important enough to justify treating them as trumping an invocation of sovereignty, there is no necessary coincidence between them and very important, universal, or fundamental rights (Raz 2007, 14-9). But what are fundamental rights? Raz (1986, 255) says they are rights that "are part of the deepest level of moral thought." This does not mean that fundamental rights are those about which one thinks deeply, while other rights only call for less engaged moral thinking. To understand what Raz means, we need to remember that the ITR offers a philosophical definition of rights: since his reflections on "fundamental rights" are offered as part of this conceptual analysis, he is not thinking of the layperson's use of that expression. 


\section{RAZ ON RIGHTS}

In common parlance, by fundamental rights we mean important rights - often deferring to bills of rights for an identification of what they are. These documents encourage the conflation between fundamental and human rights - eg, the European Human Rights Convention's extended title refers to "human rights and fundamental freedoms." When theorists, however, apply "fundamental" as a qualifier to "right" they do not (or should not) use it in that loose sense. Rather they use it (or should use it) in a sense analogous to the way in which Finnis conceives of the "basic goods." For Finnis $(2011,23)$, "[t]here is a set of basic practical principles which indicate the basic forms of human flourishing as goods to be pursued and realized, and which are ... used by everyone who considers what to do." These Finnis calls the basic goods. For Finnis, these goods (life, play, knowledge, etc) ground the value of everything else that is of value; they are basic or fundamental because they are foundational to other goods. At the same time, their own value is self-evident: it is incapable of being justified by reference to anything deeper, or more basic, than itself (Finnis 2011, 649).

Raz seems to assume that the philosophical concept of fundamental rights ascribes them a status similar to that of Finnis's basic goods. Rights theorists speaking of fundamental rights may mean, therefore, (a) that the relevant right is self-grounding - ie, its value is not built on a more fundamental good than the right itself. Often, however, they also mean (b) that the right is fundamental in the sense that it is foundational to the rest of morality. While (b) presupposes (a), (a) does not necessarily entail (b).

Raz (1986, 193-216) rejects (b) - the view that all sound moral propositions can ultimately be reduced to statements about people's fundamental rights (as we will see in the next section, he also inclines towards rejecting (a)). But he rejects (b) for reasons independent of his philosophical account of the concept of rights. Thus one can disagree with Raz and 


\section{RAZ ON RIGHTS}

maintain that some rights are foundational to morality, while holding on to the ITR. Indeed, the ITR aspires to illuminate all theories of rights, including those committed to (b).

Because, as I argued, (b) (the view that morality is rights-based) presupposes (a) (the idea that some rights are morally fundamental in the sense of self-grounding), in order for the ITR to be compatible with (b), the ITR needs to make room for (a). Yet, Raz worries (1986, 191), by making rights dependent on interests, his account seems to rule out that rights can ever be morally fundamental in the sense that there is no source of value deeper than these rights: if rights are always grounded in interests, then those interests are always more fundamental than the rights which are grounded in them. Raz (1984a, 213) resolves this puzzle by arguing that sometimes the interest grounding a right may be an interest in having that right. This rescues the idea that there are morally fundamental rights: these are those grounded in interests which are not prior to the rights themselves. Raz (1984a, 213) claims that this is not fatally circular. He also stipulates that the interest in having the right which grounds morally fundamental rights must be of ultimate value: its value must "not derive from some other interest of the right-holder or of other persons" (Raz 1984a, 214). Without this, we would be returned to an interest more fundamental than the right grounded in it.

In sum, Raz formulates the idea of rights grounded in the ultimate value of the interest in having the right itself in order to make his philosophical definition of rights capable of accounting for a (controversial) view to which he is not committed, but which presupposes the existence of morally fundamental (ie self-grounding) rights - namely, the view that morality is rights-based.

\section{Are there any morally fundamental rights?}

Does the idea of rights grounded in an interest in having the right itself do any work other than enable the ITR to account for rights-based moralities (which Raz thinks are flawed)? Raz 


\section{RAZ ON RIGHTS}

(2010, 35) apparently does not think so: without much elaboration, he recently voiced some doubts about the proposition that there are any rights that are genuinely self-grounding. In this section I argue that Raz is probably right in doubting that there are self-grounding rights.

The idea of a right whose sufficient ground is the value of the interest in having the right itself is, albeit tortuous, intelligible. It is hard, however, to believe that the value of any such interest could, as required by the definition of morally fundamental rights, be ultimate rather than derived from the value of another interest. I will begin by drawing upon Sen's work in order to attempt to make the best case I can for the proposition that self-grounding rights exist; I will then show that the attempt fails.

If, as traditional theorists of human rights argue, human rights are our most important rights, the list of morally fundamental (ie self-grounding) rights - assuming they exist - may partially coincide with some of the human rights identified in traditional theories. Sen (2004) has recently developed such a traditional theory, identifying human rights with those important moral rights that protect freedoms related to human basic capabilities and impose ethical demands (19). Sen believes that respect for human rights thus understood requires one to attend to both the "opportunity" and "process" aspects of relevant freedoms. Violations of the opportunity aspect of freedoms involve the removal of the option to do what one would like to do (or not to do what one does not want to do). As an illustration of the violation of the process aspect of freedom, on the other hand, Sen $(2004,330-8)$ offers the example of forcing someone to do what they would otherwise willingly do. The illegitimacy of violations of the process aspect of human rights-related freedoms may look like a promising start for substantiating the argument that some rights' sufficient ground is the ultimate (ie nonderivative) value of the interest in having the right itself. If this argument could be substantiated, it would follow that morally fundamental (self-grounding) rights exist. But I don't think it can be substantiated. 


\section{RAZ ON RIGHTS}

First let me dispose of an objection - namely, that there is no right whose exclusive ground is the intrinsic importance of the interest in having the right itself. The response is that nothing in the Razian definition of morally fundamental rights requires that morally fundamental rights be grounded only in the interest in having the right. To believe in morally fundamental rights all we need to accept is that the ultimate value of the interest in having the right is sufficient to ground the right; this does not entail that the interest in the right's object cannot be a sufficient ground too.

Take now the right to be a parent. In most cases it is appropriate to see it as being grounded in the interest in the right's object - ie, a life with children. Consider, however, the case of someone who is forcibly sterilised despite not intending to have children. Quite apart from any violation of bodily integrity, this would be, in Sen's terms, a violation of the process aspect of their freedom to be parents: it is not just a violation of the opportunity aspect, because the badness of the forced sterilisation is not merely contingent on the possibility that in the future the sterilised person might change their mind about having children. This example may show that it is sometimes appropriate to see the right to be a parent as grounded in an interest in having the right itself, rather than an interest in the right's object (namely, a life with children). The interest in having the right to be a parent is a sufficient ground for the duty not to forcibly sterilise even those who do not wish to procreate because the right to be a parent gives meaning to their choice not to be parents. On this view, the right to be a parent seems over-determined - its sufficient ground is, as the case may be, either the interest in a life with children or the interest in having the right to be a parent. Does then the right to be a parent's ability to rule out violations of the process aspect of the freedom to be a parent supply an example of a morally fundamental right? It all depends on whether the interest in having the right which is a sufficient ground for the right is such a ground on account of its 


\section{RAZ ON RIGHTS}

ultimate (rather than derivative) value. If not, then we are not facing a genuine case of selfgrounding right.

Let me consider some possibilities. I have already argued that what makes the interest in having the right to be a parent a bar to the sterilisation of someone who does not want children cannot be the value of parenthood to the right-holder. The value of having the right also does not derive from the value of that person's reproductive capacities to others: the importance of my interest in having the right to be a parent, if it is a sufficient ground to hold the state duty-bound not to forcibly sterilise me even if I don't ever want children, does not derive from your interest in using me as a sperm donor, or from my parents' interest in grandchildren. But there are other possibilities which, unlike those just explored, cast serious doubt on the ultimate (underived) value of the interest in having the right to be a parent. Specifically, the value of this interest, I suggest, derives from the ways in which we collectively value parenthood (which either invests parenthood with value, or is evidence of its objective value), hence from people's interest in a life with children. What makes us conclude that the interest in having the right to be a parent is a sufficient ground for the duty not to forcibly sterilise even those who don't want children is our awareness that a life with children may be a singularly valuable form of life. It seems impossible to account for the value of the interest in having the right to be a parent without reference to the fact that to a great many people it is a matter of extraordinary importance to partake to a life with children. In sum, it seems implausible that the interest in having the right to be a parent is of sufficient importance to ground a right to be a parent merely on account of its ultimate value. Its value is largely and perhaps entirely derived from people's interest in (or the value of) a life with children. If the right to be a parent is, as I think, representative of other potential candidates for the title of self-grounding rights, it seems that there are no such rights. 


\section{RAZ ON RIGHTS}

Raz's recent remarks about rights and their value confirm this. As $\operatorname{Raz}(2010,36)$ explains, rights are justified by their value to the right-holder, which includes: a) the value of what one has a right to (ie, the value of the right's object); b) the "value of the secure enjoyment of that object" (the point of rights is precisely to facilitate the control over their object by establishing duties in others); and c) the "exchange value of the right". "Exchange value" means that if the right is alienable, then, while its object may be of little value to you, the right itself is still valuable if you can transfer it to someone to whom the object is valuable. The Picasso you inherited may be of no value to you, but your right over it has considerable exchange value.

Raz (2010, 33-4) says that these are truisms that do not qualify his conceptual analysis of rights. I disagree. To say that the right's object or the right itself is "of value" to the rightholder is equivalent to saying that the right-holder has an interest in them. Thus, to say that a right's value to the right-holder grounds the right, as Raz has recently stated, is the same as saying that rights are grounded in the interest in having them. This is a refinement of the proposition - to which the earlier Raz was committed - that some rights (ie, morally fundamental rights) may be grounded in an interest in having the right itself. In any case, the important implication of Raz's recent remarks is that the interest in having the right itself is dependent on and includes the interest in the right's object - if not my interest in it, then at least other people's. But if the value of the interest in having the right is derivative in this way, then there are no self-grounding rights: the interest in the right's object is always prior to the right itself and to the interest in having the right.

\section{Qualitative ways of resolving rights disputes}

I now turn to the question of whether the ITR can accommodate "qualitative" methods of resolving conflicts between rights, or between rights and other moral considerations. If it 


\section{RAZ ON RIGHTS}

cannot, then it fails to illuminate the arguments of an increasing number of participants in philosophical and constitutional discourse about rights. The question arises in relation to constitutional and human rights.

At one end of the spectrum of constitutional (and human) rights adjudication theories, are those who assert that rights are on par with other values. Any conflict involving rights must be solved by pragmatically deciding which is most important in the concrete case, assigning a concrete weight to each value having regard to all contextual features of the case: "No a priori judgment may foreclose the empirical analysis" (Tremblay 2014, 885). I refer to this as the quantitative method of resolving rights disputes.

Those in the opposed camp respond that if constitutional rights can give way to other values or moral considerations, then it is pointless to entrench them in bills of rights (Tsakyrakis 2010). From this perspective some rights are qualitatively different from the moral considerations that conflict with them: they mark out certain values that have (or usually have) "lexical priority" (Waldron 1989) over other (or some other) moral considerations. On this view, an abstract judgement about the importance of each right relative to conflicting values motivates its entrenchment as a constitutional or human right. A decision-maker deciding a case in which these rights collide with other values (or with other rights) needs to reconstruct or work out this abstract order of importance.

The middle ground between the position that rights disputes should be resolved using the quantitative method of pragmatic balancing and the position that rights have lexical (qualitative) priority over other values is covered by approaches that combine features of both. Klatt and Meister (2012: 690) argue that although rights need to be balanced against conflicting considerations on the basis of their concrete weight, this exercise is preceded by an evaluation of their abstract weight - namely, "the weight that a principle possesses relative to other principles, but independently of the circumstances of any concrete case." Taking 


\section{RAZ ON RIGHTS}

rights' abstract weight into account does not give rights categorical priority over other considerations, or some rights categorical priority over others. But it gives them "a winning margin": the greater the right's abstract weight the harder for the right to be defeated by a conflicting value (Klatt and Meister 2012, 690; 2012a, 29). Borowski (2013, 1417) argues along similar lines. Meyerson's (2007) argument that decision-makers balancing rights against the public interest in concrete cases should artificially inflate the weight assigned to the right is a way of operationalising a similar insight.

Conceiving of rights as having abstract weights that create a presumption in their favour is not the only way of establishing qualitative preference relations between them or between them and other considerations. For example, Möller argues (2012, 143-69) that many rights disputes are resolved on the basis that we do not have rights whose exercise results in harming others. ${ }^{3}$ This is the same as saying that your right will tend to take priority over my right to pursue a project that would interfere with it, regardless of the fact that the interest grounding your right may be less weighty than mine. As in the case of abstract weight, however, Möller's harm principle only establishes a rebuttable presumption. When there is "extreme disparity" between the benefit accruing from the right and the harm it causes, the presumption against the offending right can be rebutted by balancing the concrete weights of the values in conflict (Möller 2012, 146-7).

There is at least one more method of resolving rights disputes qualitatively. Waldron $(1989,516)$ suggests that rights have automatic priority when there is an "internal" relation between the right and the conflicting consideration. I will use Pildes' analysis of US constitutional practice (1998) to explain and restate Waldron's idea of "internal relations" in a way that makes it intelligible from the point of view of the ITR. Pildes (1998) argues that US

\footnotetext{
${ }^{3}$ For Möller "harm" means a interfering with others' autonomy interests; and such interests are themselves the ground of prima facie rights. It follows that harm is an invasion of other people's rights.
} 


\section{RAZ ON RIGHTS}

constitutional practice protects rights less out of concern for the interests of rights-holders than because they enable the flourishing of common goods; and whether or not a certain right prevails in a conflict between it and some counter-consideration depends on the congruence between the reason for infringing the right and this good. Where there is no congruence, the infringement is unjustifiable and the right prevails; for example, conditioning voting rights on payment of state poll taxes is not consistent with a proper understanding of the common good of democracy and as such is not a good reason for infringing the right to vote (Pildes 1998, 732-4, 745-6). Now recall Raz's argument that sometimes an individual interest has the requisite importance to ground a right thanks to its instrumental value to the community rather than merely on account of its intrinsic value to the right-holder. Pildes' argument that rights under the US Constitution are there to protect common goods can be understood just in these terms. To say that right claims will prevail when there is no congruence between the reason for infringing the right and the common good protected by the right can then be seen as a special case of a more general proposition: a right will prevail over conflicting considerations when there is no congruence between the reason for infringing the right and the reason for recognising it (whether or not the latter has anything to do with common goods). To elaborate on Waldron's idea of internal relations, then, we could say that certain reasons for infringing a right are ruled out as unjustifiable by the very raison d'être of that right: the exclusion of certain reasons from the realm of those that may justify an infringement of a right is inbuilt into the reasons for recognising the right.

Consider, as an example, the case of an abductor refusing to disclose his victim's whereabouts. The victim is about to starve to death. Should the police resort to torture to extract the information? The balancing approach would seem to recommend doing so: isn't the victim's interest in their life weightier than the abductor's bodily integrity? Even when abstract weights are considered it may seem illogical to assign more weight to freedom from 


\section{RAZ ON RIGHTS}

torture than life. The idea of internal relations enables us to account for the reasons why many of us feel uncomfortable with this outcome. Suppose the reason for recognising a right to be free from torture is largely the principle that people should never be treated merely as means to an end. On this view, the right to be free from torture by definition rules out that there can ever be good reasons to violate the duty not to torture: any violation of that duty, however commendable the motives of the torturer, automatically treats people merely as means (incidentally, this may not be true of other duties grounded in the right to be free from torture: it is the duty not to torture that is absolute, not the right).

Thus, scholarship on rights that post-dates the ITR has identified at least three different ways in which qualitative considerations may be relevant to resolving rights disputes: abstract weight; the harm principle; and the internal relations approach. While the abstract weight and harm principle approaches admit of being qualified by the quantitative method, the internal relations approach, as reconstructed above, seems to displace it.

\section{The ITR vis-à-vis qualitative ways of resolving rights disputes}

The debates I have discussed in the previous section are clouded by terminological disagreements - particularly in respect of the term "balancing". Tremblay (2014) confines the use of the term to what I called the quantitative method - namely, the contextual assessment of concrete weights; he sees all qualitative ways of resolving right disputes (including the assessment of abstract weight) as belonging to an alternative model, which he calls the "priority of rights" model. Klatt $(2014,894-7)$ disagrees - his main point being precisely that abstract weight assessment is part and parcel of balancing. Others also include the assessment of abstract weights under the umbrella of "balancing” (Borowski 2013, 1416). Möller (2012, 137-40) goes further, concluding that the language of balancing, ubiquitous in constitutional rights adjudication, accommodates both quantitative and qualitative approaches. Conversely, 


\section{RAZ ON RIGHTS}

Kumm (2007), like Tremblay, narrows the concept of balancing down to those cases where the conflict is resolved by the quantitative method, arguing that the constitutional language of balancing and proportionality obscures those cases in which qualitative approaches are appropriate.

Raz's (1984a: 200, 209) terminology - where he speaks of the importance of an individual interest being "outweighed" by counter-considerations, and about the "weight" of such considerations - invites the interpretation that, according to the ITR, the resolution of right disputes involves the quantitative method of balancing concrete weights. While this terminology is also consistent with the qualitative exercise of assessing abstract weights, it does not seem to cover cases in which rights disputes are resolved using the other two qualitative methods I discussed - the internal relations approach and the harm principle. Some observations that Raz himself makes elsewhere confirm this interpretation by suggesting that his terminological choices are deliberate. $\operatorname{Raz}(1999,48)$ notes that "the indiscriminate application of the terminology of 'weight', 'strength', 'overriding', 'on balance', etc." obscures the fact that we "use different modes of reasoning to support different practical conclusions". The mode of reasoning which is not adequately captured by the terminology of balancing and weights is the approach that involves making decisions on the basis of "exclusionary reasons" (Raz 1999, 35-48). Exclusionary reasons are second-order reasons that exclude and replace first-order reasons for or against a particular course of action. Thus, the fact that I promised you to do something is a second-order reason for doing it and excludes whatever first order reasons there may now be against my doing it. The resolution of rights disputes in accordance with the qualitative "internal relations" method I discussed above is precisely an example of reasoning on the basis of exclusionary reasons (cf Porat 2006, 140214, 1420-21; Meyerson 2007, 878-84): the approach excludes certain reasons from the realm of justifications for infringing a particular right whenever these reasons are incongruent with 


\section{RAZ ON RIGHTS}

the reasons for protecting it, regardless of the relative strength of each set of reasons. Similarly, the harm principle excludes (except in cases of extreme disparity) the relevance of the reasons for protecting a particular right when exercising the right results in harming others, regardless of the weight of the harm relative to the importance of the interest protected by the right. If the harm principle and the internal relations approach are examples of reasoning on the basis of exclusionary reasons, and if this reasoning is just what Raz says a rigorous use of the terminology of weights and balance does not cover, his use of that terminology in the ITR seems to amount to a rejection of those qualitative methods of resolving rights disputes that follow the pattern of decision-making based on exclusionary reasons. In my experience, this is just what legal philosophers often assume: that the ITR can only envisage resolving rights disputes by balancing concrete (and perhaps abstract) weights.

The first point in response to this is that even if Raz's terminological choices are deliberate, there is no reason to feel enslaved by them. As far as I can see, nothing in the ITR logically precludes the recognition that there are cases where rights disputes are appropriately resolved through qualitative methods based on exclusionary reasons. My second point is that those who read Raz's work may be too quick in concluding that his terminology rejects these methods. Let me quote Raz again:

Where the conflicting considerations outweigh the interest of the would-be right-holder ... then there is no right. Where the conflicting considerations override those on which the right is based on some but not all occasions, the general core right exists but the conflicting considerations may show that some of its possible derivations do not. (Raz 1984a, 211)

The immediate object of this passage is to explain the conditions for the existence of rights. It is only by implication - and only in the second sentence - that the passage deals with rights 


\section{RAZ ON RIGHTS}

adjudication (as I argued, rights adjudication involves judgements about whether a core or intermediate right grounds the specific derivative right that the claimant is asserting). The first sentence states that an assessment of weights is required in order to decide whether a core right exists at all. The relevant questions will be, I suggest: Is this interest, conceivably, important enough in the abstract to outweigh conflicting values and ground duties in others? And can we envisage real-life scenarios in which the interest would ground particular duties correlative to specific derivations of the right? If the answer to these questions is Yes, then the right exists as a core right.

This test of existence involves balancing (both abstract and concrete) weights and this is appropriately reflected in Raz's $(1984 a, 211)$ use of "outweigh" in the first sentence. In the reprint (Raz 1986, 184) of his essay on the nature of rights, the first sentence is rephrased: "[W]here the conflicting considerations altogether defeat the interests of the would be rightholder, or when they weaken their force..." "Outweigh"; "defeat"; "weaken their force": these terms are all correct here because neither the internal relations approach nor the harm principle (whose reasons-excluding effect is not adequately covered by these terms) are relevant to the question of establishing whether a core right exists. Rather, both the internal relations approach and the harm principle come into play after the existence of a core right has already been established, respectively to confirm or deny that some of its derivations can be established. The internal relations approach can be seen as parasitic on the abstract weight of the interest which grounds the core right: whatever accounts for the interest's sufficient importance also excludes that some reasons will be acceptable grounds for limiting the right. As to the harm principle, it applies across the board to all core rights once these have already been independently established and enables one to conclude that some derivations of the right cannot be justified. Since neither the harm principle nor the internal relations approach contribute anything to the question of whether a core right exists, it is appropriate for Raz's 


\section{RAZ ON RIGHTS}

terminology to foreground weights rather than reasons-excluding relations in the first sentence of the passage I quoted.

Conversely, when one needs to decide whether a core right grounds particular derivative rights - and I have argued that this is just what is involved in, among other things, constitutional or human rights adjudication - reasons-excluding approaches are potentially relevant alongside a consideration of rights' abstract and concrete weights. Accordingly, Raz's (1984a, 211) terminology shifts from "outweigh" to "override" in the second sentence of the passage. "Override" captures either the idea of outweighing (as in balancing weights) or excluding (as in the harm principle and the internal relations approach).

In short, the ITR is neither logically nor terminologically committed to the view that all rights disputes must be resolved through balancing the weights of conflicting values. What the theory does rule out is that rights are thinkable other than by reference to interests. The early Dworkin (1981) (convinced that grounding rights in interests was "inadequate"(210)) attempted such a conceptualisation of rights. But Raz (1984a, 195), despite his aspiration to illuminate all different theories of rights, always conceded that his definition did not have much in common with Dworkin's analysis. The ITR also rules out that the resolution of rights disputes is always a matter of deciding on the basis of exclusionary reasons. But since the attempt "to avoid any balancing by means of establishing strict priorities between colliding interests ... cannot be successful" (Klatt 2014, 894), nothing is lost by the ITR's failure to account for uses of the word "right" that are committed to this attempt.

\section{Conclusions}

The upshot of this article is that Raz's conceptual analysis of rights continues successfully to illuminate moral, political and legal writing about rights into the twenty-first century, including (and especially) writing on constitutional and human rights adjudication. Raz's 


\section{RAZ ON RIGHTS}

recent controversial remarks about human rights are not part of this conceptual analysis. One can subscribe to the ITR without buying into Raz's theory of the practice of human rights. One area of the ITR that has remained relatively obscure surrounds morally fundamental rights. Albeit stating the ITR in a way that accounts for the view that morally fundamental rights exist, Raz is correct in thinking that there are probably no such rights.

University of Reading, School of Law

Foxhill House, Whiteknights Road

Earley, Reading, RG6 7BA, UK

E-mail: a.zanghellini@reading.ac.uk

\section{References}

Alexy, R. 2002. A Theory of Constitutional Rights. Oxford: Oxford University Press.

Borowski, M. 2013. On Apples and Oranges. Comments on Niels Petersen. German Law Journal 14: 1409-18.

Finnis, J. 2011. Natural Law and Natural Rights. Oxford: Oxford University Press. (2 ${ }^{\text {nd }}$ ed.)

Klatt, M. 2014. An Egalitarian Defense of Proportionality-Based Balancing, A Response to Luc B. Tremblay. International Journal of Constitutional Law 12: 891-9.

Klatt, M and Meister, M. 2012. Proportionality - A Benefit to Human Rights? Remarks on the ICon Controversy. International Journal of Constitutional Law 10: 687-708.

Klatt, M and Meister, M. 2012a. The Constitutional Structure of Proportionality. Oxford: Oxford University Press.

Kumm, M. 2007. What Do You Have in Virtue of Having a Constitutional Right? On the Place and Limits of the Proportionality Requirement. In Law, Rights, Discourse: Themes Of The Work Of Robert Alexy. Ed. S. Paulsen and G. Pavlakos. Oxford: Hart. 


\section{RAZ ON RIGHTS}

Liao, S. M. and Etinson, A. 2012. Political and Naturalistic Conceptions of Human Rights: A False Polemic? Journal of Moral Philosophy 9: 327-52.

Meyerson, D. 2007. Why Courts Should Not Balance Rights against the Public Interest. Melbourne University Law Review 31: 873-902.

Möller, K. 2012. The Global Model of Constitutional Rights. Oxford, Oxford University Press.

Pildes, R.H. 1998. Why Rights Are Not Trumps: Social Meanings, Expressive Harms, and Constitutionalism. The Journal of Legal Studies 27: 725-53.

Porat, I. 2006. The Dual Model of Balancing: A Model for the Proper Scope of Balancing in Constitutional Law. Cardozo Law Review 27: 1393-448.

Raz, J. 1984. Legal Rights. Oxford Journal of Legal Studies 4: 1-21.

Raz, J. 1984a. On the Nature of Rights. Mind 93: 194-214.

Raz, J. 1986. The Morality of Freedom. Oxford: Oxford University Press.

Raz, J. 1999. Practical Reason and Norms. Oxford: Oxford University Press.

Raz, J. 2007. Human Rights without Foundations. Oxford Legal Studies Research Paper No. 14/2007. SSRN: http://ssrn.com/abstract=999874.

Raz. 2010. Human Rights in the Emerging World Order. Transnational Legal Theory 1: 3147.

Raz, J. 2013. On Waldron's Critique of Raz on Human Rights. Oxford Legal Studies Research Paper No. 80/2013. SSRN: http://ssrn.com/abstract=2307471.

Schaber, P. 2011. Human Rights without Foundations? In The Philosophy of Human Rights. Ed. G. Ernst and J. C. Heilinger. Berlin: De Gruyter.

Sen, A. 2004. Elements of a Theory of Human Rights. Philosophy \& Public Affairs 32: 31556. 


\section{RAZ ON RIGHTS}

Tasioulas, J. 2013. Human Rights, Legitimacy, and International Law. American Journal of Jurisprudence 58: 1-25.

Tremblay, L. 2014. An Egalitarian Defense Of Proportionality-Based Balancing.

International Journal of Constitutional Law 12: 864-90.

Tsakyrakis, S. 2009. Proportionality: An Assault on Human Rights? International Journal of Constitutional Law 7: 468-93.

Waldron, J. 1989. Rights in Conflict. Ethics 99: 503-19.

Waldron, J. 2013. Human Rights: A Critique of the Raz/Rawls Approach. NYU School of Law, Public Law Research Paper No. 13-32. SSRN: http://ssrn.com/abstract=2272745.

Webber, G. 2013. On the Loss of Rights. LSE Legal Studies Working Paper No. 16/2013. SSRN: http://ssrn.com/abstract=2272978. 